\title{
0323 URBAN-RURAL DIFFERENCES IN SCHOOL INJURY PATTERNS: FINDINGS FROM 34 CITIES IN 2005-2007
}

J Hong*, J Pil Cho Correspondence: Center for Community Safety Promotion, School of Medicine, Ajou University, \#5, Wonchon-dong, Yeongtong-gu, Suwon City, 443-721, Republic of Korea

\subsection{6/ip.2010.029215.323}

To examine patterns of school injuries among kindergarten, primary, middle, high school and special school students by level of urbanisation in 34 cities.

School injuries reported to School Safety Insurance Federation in Kyunggi province, South Korea from 2005 to 2007 were analysed. Urbanisation levels were categorised into three groups based on urbanisation rates produced by Ministry of Land, Transport, and Maritime Affairs. Injury patterns were examined taking into account sex, school level, injury mechanism, injury factor, injury time, body part injured, month and day injured and remuneration.

During study period, a total of 18787 students were injured at schools in 34 cities. Percentages of injuries in boys were higher in most urbanised areas than in least urbanised. We found a significant difference by school levels. In most urbanised areas, kindergarten students were more likely to sustain injuries and middle school students were least likely to be injured. Caught in something was more prevalent in most urbanised areas. Injuries by doors/windows/floors/walls and fires/hot water were more prevalent in most urbanised areas, but injuries by persons/animals/plants showed opposite results. In least urbanised areas, more injuries occurred on the way to or from school and during cleaning time and arms were injured most often. Urbanisation levels and injury percentages showed a positive correlation in March, July and August and an inverse correlation in January, April and June.

Since patterns of school injuries vary by urbanisation levels, more differentiated intervention efforts, which consider regional characteristics are needed. 